\title{
Occupational and Medical Radiation Exposures in Regional Hospital of Gjirokastra City, Albania
}

\author{
Antuela Sinani ${ }^{1}$, Kostandin Dollani ${ }^{2}$ \\ “Eqrem Çabej” University, Gjirokastra, Albania ${ }^{1}$ \\ Radiation Protection Institute, Tirana, Albania ${ }^{2}$
}

\begin{abstract}
Radiological examinations nowadays provide a significant benefit in the field of the health care. The question of such examinations is to balance their benefits to the risk associated intending to the reduction of the patent dose. This study aims to measure occupational doses and to assess the patient dose by radiological examinations, performed in the regional hospital of Gjirokastra city for the most frequent radiological examinations performed in this hospital The TLD-100 Harshaw dosimeters were used for this purposes calibrated in SSDL. The dose of medical staff as well Entrance Surface Dose (ESD) for patients were measured as the basic dosimetric quantities. These quantities were measured and averaged for medical staff and for ten patient doses for each examination. The obtained values for occupational exposures and patients doses generally were in accordance with IAEA standards for occupational exposures and guidance levels for medical exposures. The measuring of occupational exposures and the radiological examinations doses will contribute for development and improvement of the national radiation protection program for occupational and medical exposures.
\end{abstract}

Keywords: Occupational Exposure, Medical Exposure, Entrance Surface Dose, TLD.

\section{INTRODUCTION}

Occupational and medical exposures are a great concern for the medical staff and the patients. The medical staff related with radiation sources of radiation diagnostic and therapy are subject to doses by these sources as radiography, fluorography, CT etc. The patient dose is also in great increment as result of entering new radiation devices. Based in the data of UNSCEAR the world annual average number for $\mathrm{X}$ ray medical examinations is 3,5 billion. (UNSCEAR 2010) Since the introduction of the diagnostic reference levels (ICRP 1996), (IAEA 2001) there have been continuing worldwide efforts to develop and implement them in diagnostic radiology as well to nuclear medicine. DRL can serve to avoid to the patient dose that does not contribute in medical diagnoses. From the other hand DRL can serve to implement the optimization process during $\mathrm{X}$ ray examinations with intention having good quality images with low patient dose [1], [2], [3].

The dose for medical staff is measured as general rule by thermo luminescent dosimeters which are taken by staff for e period of two moths. From the other hand Entrance Surface Dose (ESD) is one of the basic dosimetric quantities for measuring the patient dose and a suitable mean for optimization purposes and for comparison with the diagnostic reference values. ESD value measurement for patient serves also as basic component of the quality assurance program for X-ray radiology departments ESD is a measure of the absorbed dose by the skin at the entrance point of the X-ray beam.

ESD measurement can be performed directly by TLD or ionization chambers and in diagnostic radiography it is proportional to factors such as the tube current, exposure time, the tube voltage, filtration and collimation of $X$ ray beam and patient size (Parry et al. 2002).
For the patient it is important to put in evidence that imaging with ionizing radiation is associated with a risk for stochastic detriments as cancer induction or genetic detriment. ESD and effective dose can serve as a good index for evaluation of such detriments [4].

\section{MATERIALS AND METHODS}

In our study thermo luminescent dosimeters (TLD-100 Harshaw, Fig.1) were used for direct ESD measuring during the patient exposure process. For that purpose for a certain examination the TLD dosemeters were put in the X ray patients beam. We have measured five exposures for each examination and found an averaged value for the ESD.

For comparison of our results with theoretical ones we used the relationship between $\mathrm{X}$ ray tube output and kilo voltage (Fig.2), given by Archer (Archer et al. 1994) [5]. The relationship between $\mathrm{X}$ ray tube dose output $(\mathrm{mGy} / \mathrm{mA} \cdot \mathrm{min})$ in $1 \mathrm{~m}$ distance and tube kilovoltage is as follows:

$$
\text { Dose }=1,222-0,0564 \times k V+0,001227 \times k V^{2}-3,136 E-6 k V^{3}
$$

Professional exposures of medical staff of Gjirokastra Hospital are measured with the help of TL-dosimeters that kept these dosimeters for a period of two months. After this period the dosimeters are measured by emphasizing the taken dose by each doctor or radiological technician of this hospital.

The personal dosimeters (TLD-100 Harshaw, Fig.1) are kept by the employees that are exposed to ionizing radiation for two months period after which they are measured. 

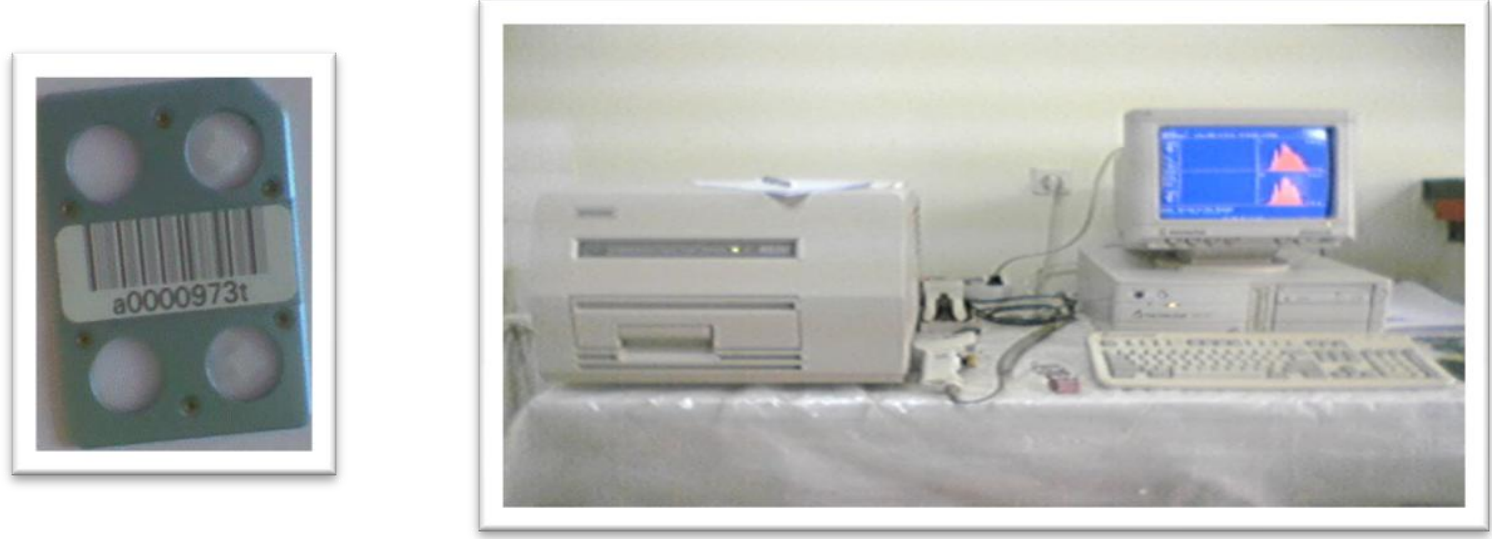

Fig1. Dosimeters TLD-100

Dosimetric system Harshaw 4500

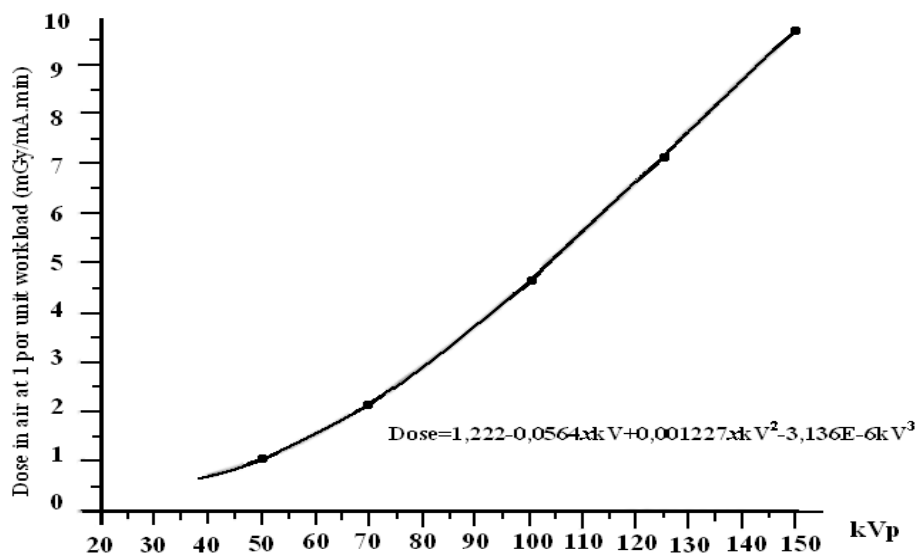

Fig.2 Relationship between $X$ ray output and kilovoltage

\section{III.RESULTS}

The first performed measurements were related with radiography of different organs. We have measured the ESD for three types of examination and namely for thorax, abdomen and extremities as well as doses taken by medical personnel of Gjirokastra hospital.

The results for these measurements by TLD are represented in the Table 1.

\begin{tabular}{|l|l|l|l|}
\hline $\begin{array}{l}\text { Type of } \\
\text { examination }\end{array}$ & $\begin{array}{l}\text { Value } \\
\text { of } \mathbf{k V}\end{array}$ & $\begin{array}{l}\text { Value of } \\
\text { mAs }\end{array}$ & ESD $(\mathbf{m S v})$ \\
\hline Thorax & $\mathbf{6 0}$ & $\mathbf{1 0}$ & $\mathbf{0 , 3 2}+\mathbf{0 , 0 7}$ \\
\hline Abdomen & $\mathbf{7 5}$ & $\mathbf{5 0}$ & $\mathbf{2 , 8 5}+\mathbf{0 , 3 1}$ \\
\hline Extremities & $\mathbf{5 0}$ & $\mathbf{6}$ & $\mathbf{0 , 1 5}+\mathbf{0 , 0 4}$ \\
\hline
\end{tabular}

Table1. ESD for radiographic examinations

The values calculated for $\mathrm{X}$ ray output (formula 1 ), which belongs to the distance $1 \mathrm{~m}$ from the $\mathrm{X}$ ray tube (FDD) are as follows: for thorax $0,25 \mathrm{mSv}$, for abdomen $2,13 \mathrm{mSv}$ and for extremities $0,10 \mathrm{mSv}$. Considering that the FSD normally is $80 \mathrm{~cm}$ the calculated values ought to multiple to $(1 / 0,8)^{2}=1,56$ the new values are respectively $0,39 \mathrm{mSv}$ for thorax, $3,32 \mathrm{mSv}$ for abdomen and $0,16 \mathrm{mSv}$ for extremities.

Based in recommended values for ESD given by ICRP and IAEA for thorax $0,4 \mathrm{mSv}$, abdomen $10 \mathrm{mSv}$ and extremities $1 \mathrm{mSv}$ it is seen that the obtained values for radiographic procedures are less than recommended values
[2], [3].The second examinations are related with fluoroscopic ones and we have measured exposures for thorax and for abdomen. The result for these measurements is represented in Table 2.

\begin{tabular}{|l|l|l|l|}
\hline $\begin{array}{l}\text { Type of } \\
\text { examination }\end{array}$ & $\begin{array}{l}\text { Value of } \\
\mathbf{k V}\end{array}$ & $\begin{array}{l}\text { Value } \\
\text { of } \mathbf{m A}\end{array}$ & ESD $(\mathrm{mSv})$ \\
\hline Thorax & $\mathbf{8 2}$ & $\mathbf{2}$ & $\mathbf{0 , 5 1 + 0 , 3 3}$ \\
\hline Abdomen & $\mathbf{1 0 0}$ & $\mathbf{3}$ & $\mathbf{2 , 2 4}+\mathbf{0 , 7 2}$ \\
\hline
\end{tabular}

Table2. ESD for fluoroscopic examinations

In this case it is with interest to calculate the dose rate of the $\mathrm{X}$ ray machine. Based in the values of the graphic, it is possible to find the dose ratio of $\mathrm{X}$ ray machine considering the values of the kilovoltage and the current. These values are respectively $6,4 \mathrm{mSv} / \mathrm{min}$ for thorax and $14,1 \mathrm{mSv} / \mathrm{min}$ for abdomen.

ICRP and IAEA recommend for these values the limit dose rate of $25 \mathrm{mSv} / \mathrm{min}$. From the other hand we can find that the dose value for abdomen is in accordance with mentioned recommendation, while the dose value for thorax is higher than recommended value [2], [3].

We have attempted also to measure by TLD dosemeters the ESD dose values during the computed tomography for two examinations: the head and the sinuses. 


\section{International Advanced Research Journal in Science, Engineering and Technology}

Vol. 2, Issue 11, November 2015

\begin{tabular}{|l|l|l|l|}
\hline $\begin{array}{l}\text { Type of } \\
\text { examination }\end{array}$ & $\begin{array}{l}\text { Value of } \\
\mathrm{kV}\end{array}$ & $\begin{array}{l}\text { Value } \\
\text { of mAs }\end{array}$ & ESD $(\mathrm{mSv})$ \\
\hline Head & $\mathbf{1 2 0}$ & $\mathbf{1 0 0}$ & $\mathbf{2 4 , 5}+\mathbf{2 , 5}$ \\
\hline Sinuses & $\mathbf{1 2 0}$ & $\mathbf{7 5}$ & $\mathbf{1 8 , 4}+\mathbf{2 , 1}$ \\
\hline
\end{tabular}

The results for these measurements are represented in Table 3 .

These values are in accordance with reported values for analogues examinations by specialized organizations.

In table 4 there are given the doses of medical personnel

Table3. Values of organ dose for CT examinations during two months period.

\begin{tabular}{|l|l|l|l|l|l|l|l|l|l|l|}
\hline $\begin{array}{l}\text { Nr. of dosimeter of } \\
\text { medical personnel }\end{array}$ & 1 & 2 & 3 & 4 & 5 & 6 & 7 & 8 & 9 & 10 \\
\hline Equivalent dose (mSv) & 0.29 & 0.24 & 0.28 & 0.21 & 0.24 & 0.29 & 0.21 & 0.24 & 0.26 & 0.27 \\
\hline
\end{tabular}

Table 4.Values of exposure of medical personnel

\section{IV.DISCUSIONS}

The obtained values for different exposures of organ by $\mathrm{X}$ ray examinations have shown a good accordance with limits which are established by specialized organizations for such exposures. In many cases we have observed a good accordance especially for radiographic examinations.

Concerning the fluoroscopic examinations we found a good accordance for abdomen exposure and a higer exposure for thorax.

The values obtained for computed tomography have shown values which are in accordance with values reported in literature for such examinations.

For considering the exposures risk by stochastic effects it is with interest to calculate effective dose of the mentioned exposures. The effective dose as a general rule is equal with one tenth of the ESD. Therefore if we have for ESD exposures values which vary between $0,1 \mathrm{mSv}$ to $25 \mathrm{mSv}$, corresponding effective doses are between $0,01 \mathrm{mSv}$ to $2,5 \mathrm{mSv}$. By the very low values founded for effective doses we can conclude that during $\mathrm{X}$ ray examination the patients risk from stochastic effects is very small and probability of detriments occurring is very small. Nevertheless the implementation of a sound control on X ray examinations for patients is a permanent duty of medical staff.

By the results for the equivalent doses of doctors and radiological technicians of the regional hospital of Gjirokastra, there are noticed that they are in the range of $0.20 \mathrm{mSv}$ to $0.29 \mathrm{mSv}$. Taking in consideration that the limit dose for period of two months corresponding the professional exposure $(3.4 \mathrm{mSv})$ it is clear that the dose taken by the personnel during two months period is lower than $1 / 10$ of limit dose for this period.

Taking in consideration the principle of optimization of protection by radiation it can be said that the doses taken are optimized doses, that means they are not only under the limit dose but they are very small doses.

As a general rule the results of the measurements by this control are announced to each employee, while with this data it is created an archive that contains the doses taken by each employee for the period he is under personal dosimetric monitoring.

\section{REFERENCES}

[1] (UNSCEAR 2010) Sources and Effects of Ionizing Radiation, United Nations Scientific Commission on Effects of Atomic Radiation, United Nations, New York..

[2] (ICRP 1996) International Commission on Radiological Protection, Radiological Protection and Safety in Medicine, ICRP Publication 73, Annals of ICRP 26, No.2 (Pergamon Press, Oxford).

[3] (IAEA 2001) International Conference on Development and Using Dose Guidance (Reference) Levels in Radiology and Nuclear Medicine Examinations, International Atomic Energy Agency, Vienna, Austria.

[4] (Parry et al. 1998) R.A. Parry, S.A. Glaze, B.R.. Archer, The AAPM/RSNA Physics Tutorial for Residents Typical Patient Radiation Doses in RSNA Scientific Assembly, New York, USA.

[5] (Archer et al. 1994) B.R. Archer, T.D. Fewell, B.J. Conway, P.W. Quinn, Attenuation Properties of Diagnostic XRay Shielding Materials, Med. Phys., 21(9), 1499-1507. 